\title{
Diferenças e semelhanças na dupla necessidade educacional especial: altas habilidades/superdotação x Síndrome de Asperger
}

Nara Joyce Wellausen Vieira* Karolina Waechter Simon**

\section{Resumo}

O estudo foi desenvolvido a partir uma pesquisa bibliográfica em livros, artigos e teses já publicadas desde o ano de 2000, sobre as temáticas Altas Habilidades/Superdotação e Síndrome de Asperger. Os objetivos desta pesquisa foram de realizar uma busca em publicações de período de 2000 até 2011, a respeito das características comuns e diferentes ao sujeito com síndrome de Asperger e altas habilidades/superdotação, assim como, também, relacionar o número de publicações encontradas na Educação Especial e a Educação. Na fundamentação teórica apresentamos a concepção de Altas Habilidades/Superdotação de Renzulli (2004) e Gardner (2000) e na concepção de Síndrome de Asperger de Mello (2007) e Klin (2006). Ao analisarmos os dados, foram percebidas semelhanças e diferenças entre as características comportamentais dos sujeitos com Altas Habilidades/ Superdotação e os que apresentam Síndrome de Asperger. É possível apontar que existem muitas evidências que distanciam estas duas necessidades educacionais especiais e poucas semelhanças entre estas. Mas não desconsideramos que possa existir a dupla necessidade especial entre estas duas necessidades educacionais especiais, pois ainda existem poucos estudos que verificam teoricamente as diferenças e semelhanças destes sujeitos e menos ainda aqueles que investigam estas semelhanças e distinções nos próprios sujeitos.

Palavras-chave: Altas habilidades/superdotação; Síndrome de Asperger; Dupla necessidade educacional especial.

\section{Differences and similarities in double special educational needs: high abilities/giftedness x Asperger's Syndrome}

\section{Abstract}

The study was developed from a literature search in books, articles and theses that have been published since the year 2000 on the theme High Abilities / Giftedness and Asperger's Syndrome. The objectives of this research were to conduct a search on publications from 2000 to 2011, about the common and different features to the person with Asperger syndrome and high ability I gifted, and also relate the number of publications found in

\footnotetext{
* Professora Doutora do Departamento de Educação Especial na Universidade Federal de Santa Maria (UFSM). Santa Maria, Rio Grande do Sul, Brasil.

** Acadêmica do curso de Educação Especial na Universidade Federal de Santa Maria (UFSM). Santa Maria, Rio Grande do Sul, Brasil.
} 
Education and Special Education. At theoretical we present the conception of High Abilities / Giftedness of Renzulli (2004) and Gardner (2000) and in the conception of Asperger Syndrome, Mello (2007) and Klin (2006). When analyzing the data, were perceived similarities and differences between the behavioral characteristics of individuals with High Abilities / Giftedness and those with Asperger's Syndrome. It's possible point out that there is much evidence that separate these two special educational needs and few similarities between them. But do not neglect that there may be a dual disability between these two particular special educational needs, because there are still few studies that verify theoretically the differences and similarities of these subjects, much less those that investigate these similarities and distinctions in the subjects themselves.

Keywords: High Abilities/Giftedness; Asperger Syndrome; Double Special Educational Needs.

\section{Introdução}

A Educação Especial possui um público alvo de alunos, que segundo a Política Nacional de Educação Especial na perspectiva da Educação Inclusiva (2008), se delimita na educação dos alunos com deficiências, transtornos global do desenvolvimento e altas habilidades/superdotação.

Entretanto, dentro especialmente da área das altas habilidades/ superdotação existe outra temática, a dupla necessidade especial, sendo esta quando os sujeitos possuem habilidades em determinada área e apresentam em conjuntura outra necessidade educacional. Em língua portuguesa, encontram-se poucos estudos sobre essa temática. Porém, dentro da Educação Especial, o foco dessas discussões e estudos, geralmente, tem se centrado na área das altas habilidades/superdotação e Transtorno do Déficit de Atenção e Hiperatividade.

A escolha desta temática se deu principalmente pelo fato de ser pouco pesquisada e pela importância da ampliação do conhecimento nesta área do conhecimento, assim como, sobre as características semelhantes e diferentes que estes sujeitos podem apresentar.

Sendo o objetivo desta pesquisa o de realizar uma busca em publicações de período de 2000 até 2011, a respeito das características comuns e diferentes ao sujeito com Síndrome de Asperger e altas habilidades/superdotação e assim como também em relacionar o número de publicações encontradas na Educação Especial e a Educação.

\section{Metodologia}

A metodologia deste estudo consiste em uma pesquisa bibliográfica, pois se trata de um levantamento de livros, artigos e teses já publicados desde 
o ano de 2000, sobre as temáticas Altas Habilidades/ Superdotação e Síndrome de Asperger. A opção por esta metodologia se deve ao fato de ser bastante utilizada em estudos em que o objeto da pesquisa é pouco estudado (LIMA \& MIOTO, 2007).

A coleta de dados foi realizada em publicações tais como: livros, artigos e teses sobre Altas Habilidades/ Superdotação e Síndrome de Asperger, nos idiomas português, inglês e espanhol durante o período de 2000 até 2011. No entanto, há pouca publicação sobre a temática. Foram realizadas buscas em bases de dados como SciELO, Google Acadêmico, Periódicos e em sites de editoras. Após esta coleta de dados, realizou-se uma leitura em todos os materiais encontrados para obter informações sobre as características que estão sendo pesquisadas. Diante destas leituras o material encontrado foi classificado em: características comuns a sujeitos com Altas Habilidades/ Superdotação e Síndrome de Asperger e características diferentes destes mesmos sujeitos, para após ser realizada uma síntese e uma reflexão do material pesquisado.

\section{Concepção de Altas Habilidades/Superdotação}

Quando pensamos em sujeitos com altas habilidades/superdotação existem dois conceitos que devem ser explicitados: inteligência e superdotação. Dois teóricos subsidiaram nossa investigação: Howard Gardner (2000), com a Teoria das Inteligências Múltiplas, amplia os campos para os sujeitos exercitarem suas "inteligências"; e Renzulli (2004), com a Teoria dos Três Anéis, oferece uma visão sistêmica de quem é o sujeito com altas habilidades/superdotação.

Neste sentido, Gardner (2000) apresenta um conceito modular de inteligência enfocando a manifestação de várias competências de um indivíduo e enfatizando a capacidade de resolver problemas e de elaborar produtos reconhecidos como positivos pela cultura que o sujeito vive. Gardner (2000) descreve oito tipos de inteligência: linguística, lógico-matemática, espacial, musical, corporal-sinestésica, interpessoal, intrapessoal e a naturalista. Segundo este teórico, o sujeito pode apresentar um bom desempenho em uma dessas inteligências e não nas outras. Tal pensamento justifica teoricamente um fato que empiricamente era observado, ou seja, o sujeito com altas habilidades/ superdotação não é necessariamente "bom" em todas as áreas do conhecimento.

Segundo o teórico Renzulli (2004), as altas habilidades/superdotação é resultado da intersecção de três características: a criatividade, o comprometimento com a tarefa ou motivação e a capacidade acima da média. E da influência de uma rede social, constituída pela família, escola, amigos e outros. Primeiramente este teórico não levou em consideração o contexto do sujeito, sua teoria levava em consideração somente os fatores intrínsecos ao sujeito, o que ocasionou algumas críticas. Diante disso, ele efetuou uma modificação, 
inserindo uma rede, para ressaltar a importância dos aspectos sociais que servem de suporte na manifestação plena dos três grupos de traços (VIEIRA, 2005a).

As características propostas por Renzulli (1986) podem contribuir significativamente para definir quem é o sujeito com altas habilidades/superdotação, dentro de cada uma das competências, desde uma abordagem multidimensional das inteligências. Portanto, à medida que consideramos a pluralidade das inteligências, os três traços que constituem a pessoa com altas habilidades/ superdotação, em interação com o contexto, deverão estar presentes em cada um dos domínios das diferentes expressões da inteligência propostos por Gardner (2000) (VIEIRA, 2005b).

Nos estudos atuais sobre as altas habilidades/superdotação, segundo Costa, Sánchez e Martínez (1997), não se considera o indivíduo superdotado pela soma de uma série de qualidades que ele apresenta em seu comportamento, mas sim pela forma sistêmica como estas qualidades interagem entre si e com seu ambiente.

Vieira e Freitas (2011) mencionam a importância de verificar a frequência, a intensidade e a consistência com que os comportamentos de Altas Habilidades/Superdotação aparecem no repertório dos sujeitos. A frequência segundo as autoras consiste no número de vezes que esses comportamentos aparecem, a intensidade corresponde à carga energética que é depositada na tarefa, exigindo um esforço contínuo e intenso e a consistência diz respeito ao resultado final da aprendizagem do aluno, implicando em um resultado valorizado pela sociedade.

\section{Concepção de Síndrome de Asperger}

A Síndrome de Asperger é uma patologia que foi descrita em 1944, pelo médico chamado Hans Asperger, sendo chamado por ele inicialmente de psicopatia autística, que indicava um transtorno estável de personalidade, caracterizada pelo isolamento social. (MELLO, 2007)

Atualmente segundo Klin (2006) esta síndrome caracteriza-se por:

[...] prejuízos na interação social, bem como interesses e comportamentos limitados, mas seu curso de desenvolvimento precoce está marcado por uma falta de qualquer retardo clinicamente significativos na linguagem falada ou na percepção da linguagem, no desenvolvimento cognitivo, nas habilidades de autocuidado e na curiosidade sobre o ambiente. (KLIN, 2006, p. S8)

Conforme o Manual Diagnóstico e Estatístico de Transtornos Mentais IV - DSM-IV-TR (2002)르. essa síndrome esta inserida no grupo dos transtornos globais do desenvolvimento. Caracteriza-se por um prejuízo severo e persistente na interação social e pelo desenvolvimento de padrões restritos e repetitivos de 
comportamento, interesses e atividades. Segundo este manual, a perturbação deve causar prejuízo clinicamente significativo nas áreas social, ocupacional ou outras áreas importantes de funcionamento. Contrastando com o autismo, não existem atrasos clinicamente significativos na linguagem (isto é, palavras isoladas são usadas aos 2 anos, frases comunicativas são usadas aos 3 anos).

Além disso, não existem atrasos clinicamente significativos no desenvolvimento cognitivo ou no desenvolvimento de habilidades de autoajuda apropriadas à idade, comportamento adaptativo (outro que não na interação social) e curiosidade acerca do ambiente na infância (DSM-IV, 2002). Essas características são semelhantes ao que Klin (2006) descreve.

Segundo o DSM - IV (2002), o sujeito com esta síndrome possui as seguintes características:

- Comprometimento grave e persistente da interação social, incluindo a dificuldade de fazer amigos, demonstrar empatia, interpretar deixas sociais ou usar comunicação social não verbal (contato visual, postura e gestos);

- Interesses ou comportamentos restritos ou estereotipados, incluindo uma única área de interesse intenso, movimento repetitivo da mão, sensibilidade sensorial, repetição compulsiva;

- Não existe um atraso geral clinicamente importante na linguagem (exemplo: utiliza palavras isoladas aos 2 anos, frases comunicativas aos 3 anos);

- Não existe um atraso geral clinicamente importante no desenvolvimento cognitivo ou no desenvolvimento de habilidades de autocuidados próprios da idade, no comportamento adaptativo (outro que não na interação social) e na curiosidade acerca do ambiente na infância.

Segundo a autora Moore (2005), a Síndrome de Asperger apresenta algumas características que são descritas por ela dentro de cinco grandes grupos: linguagem, interação social, integração sensorial, funcionamento motor e o processamento cognitivo.

A linguagem desses sujeitos apresenta peculiaridades nas questões fonéticas (sons das letras e sílabas), semânticas (o sentido das palavras), sintaxe (gramática) e pragmática (linguagem com intenção de comunicar).

A característica fonética da linguagem desses sujeitos é a pronuncia de maneira precisa, exagerada e pedante, algumas vezes pode haver mudança da pronúncia de palavras, dificuldade em diferenças e variedade dos sons da linguagem e seguem as regras de linguagem radicalmente.

Na questão semântica eles apresentam um discurso com vocabulário e construções sofisticadas. Algumas vezes usam esse vocabulário rebuscado, mas não sabem o significado de algumas palavras e muitas vezes utilizam 
palavras baseados em vídeos, livros, programas de televisão. Podem apresentar dificuldades de iniciar uma conversa, pois ainda não aprenderam como usar as palavras adequadamente, o que muitas vezes faz como que eles inventem palavras ou usem frase que viram em vídeos ou filmes para interagir.

Na sintaxe são descritas características como a dificuldade de usar as palavras na ordem correta e a preocupação com as regras de linguagem. Em consequência desta preocupação alguns sujeitos com essa síndrome durante uma conversa não conseguem prestar atenção ao conteúdo da conversa, pois ficam checando a precisão, observando os erros de pronúncia ou gramatical. Outra característica é a tendência a usar a linguagem de maneira muito formal.

Neihart (2000) também define o sujeito com a Síndrome de Asperger conforme o DSM-IV e descreve algumas características diferentes das descritas acima como a fluência verbal ou a precocidade verbal, desenvolvimento irregular, desempenho extraordinário em determinada área de interesse e que estes sujeitos apresentam uma ampla gama de habilidades.

\section{Análise}

As Altas Habilidades/ Superdotação são consideradas uma necessidade educacional especial, pois essas necessidades decorrem de sua elevada capacidade para aprender. Estes sujeitos, geralmente, são identificados primeiramente pela habilidade acima da média, destacando-se, portanto por diferenças no seu desenvolvimento global ou em áreas específicas. Por consequência dessa diferença apresentam comportamentos acima do esperado para sua idade em determinada área do conhecimento, necessitando de um atendimento educacional especializado. Cabe destacar que estes sujeitos, via de regra, não apresentam nenhuma alteração orgânica no seu desenvolvimento. Em outras palavras, as Altas Habilidades/ Superdotação se constituem em um "(...) construto psicológico a ser inferido a partir de uma constelação de traços ou características de uma pessoa" (ALENCAR e FLEITH, 2001, p. 52).

Já a Síndrome de Asperger é classificada como uma patologia, ou seja, uma doença, que é descrita por um manual de diagnóstico clínico chamado de Manual Diagnóstico e Estatístico de Transtornos Mentais (DSM). Esta síndrome apresenta alterações orgânicas no desenvolvimento desses sujeitos o que ocasionam dificuldades em áreas importantes para o desenvolvimento pleno. Tais alterações são diagnosticadas levando em consideração cinco critérios, o primeiro é o individuo apresentar pelos menos duas manifestações de comprometimento qualitativo da interação social, outro critério é apresentar pelo menos uma manifestação de padrões restritos, repetitivos e estereotipados de comportamento, interesses e atividades, o terceiro é não apresentar atraso geral clinicamente importante na linguagem. Os dois últimos critérios analisados são a não existência de deficiência mental e não apresentar sinais que satisfazem critérios para a esquizofrenia. Estas dificuldades acarretam, por exemplo, atrasos no desenvolvimento escolar de sujeitos com esta síndrome. 
Portanto, a primeira grande conclusão a ser constatada é que há uma diferença importante em relação à classificação de cada um dos conceitos. Síndrome de Asperger constitui-se em uma patologia diagnosticada desde critérios clínicos e laboratoriais; enquanto que as Altas Habilidades/ Superdotação podem se entendidas como um conceito psicológico, traduzido pelos comportamentos observáveis manifestados pelos sujeitos, a partir do qual é possível inferir o alcance de um objetivo ou o domínio de uma capacidade (VIEIRA, 2005b).

Para melhor organizar as similaridades e diferenças, analisaremos estas características separando-as em quatro categorias: cognição, interação social, comportamento adaptativo (restritos e estereotipados) e comunicação. Antes de passar para a análise de cada categoria, faz-se importante defini-las.

Começaremos articulando a respeito das características semelhantes relacionadas com a cognição. Entre estas se destacam as características relativas à memória, onde ambas as necessidades educacionais especiais se destacam por apresentarem uma excelente memória. Característica esta que também foi apontado pelos autores Neihart (2000) e Widyorini (2000) como uma similaridade.

Como já foi mencionado, o vocabulário sofisticado esta presente em muitos sujeitos com Altas Habilidades/ Superdotação, principalmente naqueles identificados na área da linguística e também pode ser uma característica dos sujeitos com Síndrome de Asperger, pois muitos sujeitos apresentam um discurso com um vocabulário sofisticado. Gallagher e Gallagher (2002) também indicam esta semelhança a respeito do desenvolvimento linguístico, segundo eles o desenvolvimento linguístico pode ser médio ou acima da média.

Conforme Widyorini (2000), as pessoas com Síndrome de Asperger e Altas Habilidades/ Superdotação também podem apresentar precocidade na fala e leitura e tendem a usar linguagem sofisticada e formal. Benito (2009) também se refere ao vocabulário amplo e sofisticado como uma característica compartilhada entre estes sujeitos, mas salienta que diferentemente das Altas Habilidades/ Superdotação, os sujeitos com Síndrome de Asperger não compreendem os significados dessas palavras.

Além dessas características podemos citar semelhanças no desenvolvimento irregular destes sujeitos. Neihart (2000) também menciona como uma característica semelhante o desenvolvimento irregular, particularmente quando o desenvolvimento cognitivo é comparado ao desenvolvimento social e afetivo em uma tenra idade. Neihart (2000) também cita o interesse restrito em determinadas áreas como uma semelhança entre os sujeitos com Altas Habilidades/ Superdotação e sujeitos com a Síndrome de Asperger. Segundo esta autora, ambos possuem interesse por um tópico específico e em adquirir uma grande quantidade de informações factuais sobre o mesmo. 
Sobre a semelhança do desenvolvimento extraordinário em determinadas áreas, Neihart (2000) também traz como uma similaridade entre estes sujeitos: tanto os sujeitos com Altas Habilidades/ Superdotação, como os com a Síndrome de Asperger apresentam um desenvolvimento superior em determinadas áreas de interesses destes sujeitos.

Outra semelhança constatada é a de que as duas necessidades educacionais especiais não apresentam atrasos significativos na linguagem e atrasos significativos no desenvolvimento cognitivo. Gallagher e Gallagher (2002) também trazem a questão referente ao desenvolvimento cognitivo que pode ser médio ou acima da média em ambos os sujeitos deste estudo.

Outra característica, que já mencionamos anteriormente, que é muito significativa é a questão do quociente intelectual (QI), que em ambos os casos pode variar até muito superior. $\mathrm{E} a$ última semelhança relacionada à cognição refere-se a fluência e precocidade verbal, que está presente tanto nas Altas Habilidades/ Superdotação como nas Síndrome de Aspeger.

Observando as semelhanças relacionadas à categoria da cognição é possível perceber que são muitos os indicadores nessa área do desenvolvimento evidenciando assim a existência da dupla necessidade especial. Como não foi possível observar nenhuma semelhanças nas outras categorias, concluímos que os indicadores que mais aproximam essas duas necessidades educacionais especiais estão relacionadas às características referentes a cognição deste sujeitos.

No que refere as características diferentes dos sujeitos com Altas Habilidades/ Superdotação e os com Síndrome de Asperger iniciaremos expondo sobre a categoria alusiva à cognição.

Os sujeitos com Altas Habilidades/ Superdotação apresentam características que não são observadas em sujeitos que apresentam somente a Síndrome de Asperger. Tais características, que já foram citadas, consistem no alto grau de curiosidade, a atenção concentrada, o interesse por problemas filosóficos, morais, políticos e sociais e a originalidade para resolver problemas, situação em que os sujeitos com Altas Habilidades/ Superdotação demonstram sua criatividade. Em nosso entendimento esta é a principal característica que diferencia os sujeitos com Altas Habilidades/ Superdotação dos com Síndrome de Asperger. E de acordo com a concepção teórica utilizada neste estudo, Renzulli (2004) menciona que as Altas Habilidades/ Superdotação precisam ter três fatores básicos para ser identificada, no qual um destes fatores é a criatividade.

Em relação à criatividade nenhum dos autores utilizados nesta pesquisa faz alguma discussão sobre sua presença em sujeitos com Síndrome de Asperger. Diante disso ficam algumas indagações a respeito: $O$ sujeito com Síndrome de Asperger pode ser considerado criativo, já que a manutenção da rotina é uma característica importante nesta síndrome? Considerando este ape- 
go à rotina, como aparece a criatividade em sujeitos com a Síndrome de Asperger?

Assim como as Altas Habilidades/ Superdotação que não apresenta um perfil único e homogêneo, a Síndrome de Asperger também apresenta características únicas. Entre estas características do Asperger estão: a carência de perceber e o desinteresse nas tendências e modas populares, a dificuldade em se colocar no lugar do outro, a rigidez de pensamento, a dificuldade em discernir ficção da realidade, seletividade exagerada a informações ou estímulos, a dificuldade para discernir a ficção da realidade e a dificuldade em perceber o perigo.

Em nossa percepção, é na categoria sobre a interação social que estão as principais diferenças entre as duas necessidades educacionais especiais, pois os sujeitos com Altas Habilidades/ Superdotação não apresentam o comprometimento grave e persistente da interação social que os sujeitos com a Síndrome de Asperger mostram. Observa-se nestes últimos uma carência de habilidade para fazer amizades e falta de interesse em fazer amigos, situação que não se observa nas altas habilidades/superdotação, principalmente se for do tipo líder.

A outra categoria refere-se a características sobre a comunicação destes sujeitos. Nesta categoria também foram averiguados indicadores que estão presentes geralmente nos sujeitos com Síndrome de Asperger. Entre elas estão a dificuldade para iniciar ou manter conversas, dificuldade para discernir se um assunto é adequado ou não, falta de linguagem corporal adequada, incapacidade de "ler" a linguagem corporal e as expressões faciais e dificuldade em interpretar informação multimodal.

Nesta mesma categoria foram verificadas também características que aparecem somente nos indivíduos com Síndrome de Asperger, sobre a fonética da linguagem destes sujeitos, entre esta características estão a pronuncia de maneira precisa, exagerada e pedante, algumas vezes pode haver mudança da pronúncia de palavras, dificuldade em diferenças e variedade dos sons da linguagem e seguem as regras de linguagem radicalmente.

Neihart (2000) também cita essa diferença entre a linguagem desses, segundo ela os sujeitos com Asperger têm um discurso tipicamente pedante e os com Altas Habilidades/ Superdotação apresentam um discurso normal ou podem apresentar uma linguagem de um sujeito mais velho.

Na categoria sobre os comportamentos também verificamos distinções entre estes sujeitos. Os sujeitos com Altas Habilidades/ Superdotação são independentes, autônomos, perfeccionistas, persistentes, apresentam vulnerabilidade a críticas dos outros, tédio em relação às atividades curriculares regulares e tendência a questionar regras. 
E os sujeitos com Síndrome de Asperger apresentam comportamentos como interesses ou comportamentos restritos ou estereotipados, incluindo uma única área de interesse intenso, movimento repetitivo da mão, sensibilidade sensorial, repetição compulsiva (NEIHART, 2000). Segundo esta autora, às estereotipias presentes no sujeito com Síndrome de Asperger não são apresentadas por sujeitos com somente Altas Habilidades/ Superdotação. Este é um diferencial muito importante entre os sujeitos desta pesquisa, pois esta característica esta presente somente em sujeitos com apresentam algum tipo de Transtorno Global do Desenvolvimento.

Encontramos também como características somente dos sujeitos com Síndrome de Asperger a violação do espaço pessoal, contato visual mínimo, intenso ou pouco natural, expressão ou respostas afetivas inadequadas. Neihart (2000) também descreveu a respeito das diferenças da expressão afetiva, em que nos sujeitos com Asperger tendem a se apresentar como autômatos até certo ponto. E apresentam respostas diferentes do esperado, como risadas ou ataques de fúria ou ansiedade inapropriadamente. E os com Altas Habilidades/ Superdotação, geralmente, não apresentam dificuldades afetivas.

Os sujeitos com a Síndrome de Asperger apresentam comportamentos de passividade, agressividade, impulsividade, não sabem esperar sua vez na alternância de turnos das conversas (NEIHART, 2000). Segundo a autora, os sujeitos com Síndrome de Asperger apresentam comportamentos extravagantes, dificuldade em ter consciência de seus comportamentos excêntricos, estranhos. São também ultra (hiper) ou pouco (hipo) sensível e demonstram apego a rotinas. Neihart (2000) traz a questão da rotina, conforme ela os indivíduos com Síndrome de Asperger apresentam mais dificuldade em lidar com as mudanças e recusam-se a cooperar com as tarefas de aprendizado comum da escola e podem entrar em pânico e se tornarem agressivos em decorrências disto. E os com Altas Habilidades/ Superdotação expressam desprazeres e podem resistir passivamente à mudança de rotinas.

Segundo Benito (2009), a Síndrome de Asperger e as Altas Habilidades/ Superdotação possuem características que se combinam e outras que se chocam de uma maneira complexa. O número de indivíduos com Altas Habilidades/ Superdotação que apresentam isolamento social é reduzido, mas este isolamento poder aumentar junto com a Síndrome de Asperger. Podendo até as características de Síndrome de Aspeger anularem as Altas Habilidades/ Superdotação.

Além disso, conforme Benito (2009), as características das Altas Habilidades/ Superdotação podem aparecer diferentes quando combinadas com a Síndrome de Asperger. Consideramos a coexistência dessa dupla necessidade educacional especial outra questão importante, pois entendemos que essas características combinadas podem trazer benefícios aos sujeitos, como é o caso da coexistência das Altas Habilidades/ Superdotação e o Transtorno do Déficit de Atenção com Hiperatividade. Em outras palavras, autores que estuda- 
ram a coexistência destas duas últimas características demonstraram que a associação com as altas habilidades/superdotação trazem benefícios significativos para melhorar o nível adaptativo da patologia. (GERMANI,2006; OUROFINO, 2005)

Estas são questões que ajudariam os profissionais a darem um diagnóstico correto e, por conseguinte, estes sujeitos receberiam um atendimento educacional especializado adequado.

Diante dessa discussão sobre as semelhanças e diferenças entre as características comportamentais dos sujeitos com Altas Habilidades/ Superdotação e os que apresentam Síndrome de Asperger, destacamos que existem muitas evidências que distanciam estas duas necessidades educacionais especiais e poucas semelhanças entre estas. Mas não desconsideramos que estas duas necessidades educacionais especiais possam coexistir, pois ainda existem poucos estudos que verificam teoricamente as diferenças e semelhanças destes sujeitos e menos ainda aqueles que investigam estas semeIhanças e distinções nos próprios sujeitos.

\section{Conclusão}

Diante deste estudo foi possivel averiguar que é de suma importância ter claras as concepções tanto de Síndrome de Asperger quanto de Altas Habilidades/ Superdotação que subsidiam nossos procedimentos, pois isso proporciona a outros interessados na temática ter conhecimento de quais os parâmetros foram utilizados para realizar a devida pesquisa.

O que chamou muito a atenção durante este estudo foi a quantidade de publicações na área desta pesquisa. O número de publicações encontradas desde 2000 até este ano foi muito pequeno. Com isso concluímos que esta temática não teve a merecida atenção. Acreditamos que os profissionais da educação tenham se dedicado a escrever e se preocupar com os sujeitos somente com Síndrome de Asperger, Autismo, Deficiência Mental sem levar em consideração que estes sujeitos podem ter outras necessidades educacionais especiais associadas. Além disto, a visão tradicional de inteligência que se tinha no início do século passado, impossibilitava o entendimento de que uma pessoa com Altas Habilidades/ Superdotação tivesse outra necessidade educacional especial associada. A visão dicotômica da deficiência ou dos transtornos globais do desenvolvimento de um lado e a superdotação de outro é resultado desta concepção positivista. Desde a concepção modular de Gardner (2000) e a dinâmica de Renzulli (2004) é possível perceber a existência da dupla necessidade educacional especial.

Essa pequena quantidade de publicação sobre essa dupla necessidade especial se deve também ao fato de muitos profissionais da educação em geral acreditarem que o sujeito com Altas Habilidades/ Superdotação não apre- 
sentam nenhuma dificuldade associada ou não apresentam nenhuma dificuldade em outras áreas do conhecimento, o que é um equívoco.

Ressaltamos também a importância de mais estudo sobre a temática assim como pesquisas de campo para verificarmos a existência ou não dessas características semelhantes e diferentes em sujeitos com Altas Habilidades/ Superdotação e dos sujeitos com Síndrome de Asperger. Somente com os esses estudos será possível admitirmos a existência ou não da dupla necessidade educacional especial.

É importante que estudemos esta possível coexistência entre essas duas necessidades educacionais especiais, para que no âmbito escolar proporcionarmos a esses alunos um atendimento educacional especializado e uma inclusão escolar levando em consideração as suas peculiaridades. Pois nem sempre a Síndrome de Asperger e as Altas Habilidades/ Superdotação precisam de um atendimento educacional especializado visando às peculiaridades das duas necessidades educacionais especiais. Por vezes, as características da síndrome assumem o controle e nesses casos o atendimento deve ser mais voltado para atender a essas necessidades.

\section{Referências}

ALENCAR, E. S.; FLEITH, D. de S. Superdotados: determinantes, educação e ajustamento. São Paulo: EPU, 2001.

ALENCAR, E. M. L. S. de; FLEITH, D. de S. Desenvolvimento de talentos e altas habilidades: orientação a pais e professores. Porto Alegre: Artmed, 2007.

BODEN, M. A. Dimensões da criatividade/ Margaret A. Boden; Trad. Pedro Theobald - Porto Alegre: Artes Médicas, 1999.

BRASIL. Política Nacional de Educação Especial na Perspectiva da Educação Inclusiva. MEC/SEESP, Brasília: 2008.

BENITO, Y. Superdotacion y Asperger. Madrid: Eos Gabinete de Orientacion Psicologica, 2009.

COSTA, J. L. C.; SÁNCHEZ, M. D. P.; MARTÍNEZ, A. R. Modelos y estrategias de identificación del superdotado. In: SÁNCHEZ. M.D.P. (Org.) Identificación, evaluación y atención a la diversidad del superdotado. Málaga: Aljibe, 1997.

DSM-IV-TR - Manual diagnóstico e estatístico de transtornos mentais. Trad. Cláudia Dornelles; 4. ed. rev. Porto Alegre: Artmed, 2002.

OUROFINO, V. A. T. de.; GUIMARÃES, T. G. Características intelectuais, emocionais e sociais do aluno com altas habilidades/superdotação. In: FLEITH, D. de S. (Org.). A construção de práticas educacionais para alunos com altas habilidades/superdotação: v. 1: orientação a professores / organização: Deni- 
se de Souza Fleith. - Brasília: Ministério da Educação, Secretaria de Educação Especial, 2007a.

GALLAGHER, S. A. \& GALLAGHER, J. J. Giftedness and Asperger's Syndrome: A New Agenda for Education. Disponível online em: http:// www.hoagiesgifted.org/eric/fact/asperger.pdf. Acesso em 28/08/2011.

GARDNER, H. Inteligência: um conceito reformulado. Rio de Janeiro: Objetiva, 2000, $347 \mathrm{p}$.

GERMANI, L. M. B. Características de altas habilidades/superdotação e de déficit de atenção/ hiperatividade: uma contribuição à família e à escola. Dissertação (Mestrado). Pontifícia Universidade Católica do Rio Grande do Sul. Porto Alegre: 2006.

GRANDIN, T. Genius may be an abnormality: educating students with Asperger's Syndrome, or High Functioning Autism. 2001. Disponível em: http:// www.autismtoday.com/articles/Genius_May_Be_Abnormality.htm. Acesso em: 28 ago. 2011.

KLIN, A. Autismo e Síndrome de Asperger: uma visão geral. Revista Brasileira de Psiquiatria. 2006, n. 28 (supl I):S3-11.

LIMA, T. C. S.; MIOTO, R. C. T. Procedimentos metodológicos na construção do conhecimento científico: a pesquisa bibliográfica. RevistaKatál. Florianópolis, v. 10, nº esp., p. 37-45, 2007.

MELLO, A. M. S. R. de. Autismo: guia prático. 5. ed., São Paulo: AMA; Brasília: CORDE, 2007.

MOORE, S. T. Síndrome de Asperger e a escola fundamental: soluções práticas para dificuldades acadêmicas e sociais. Tradução de Inês de Souza Dias. São Paulo: Associação Mais 1, 2005.

NEIHART, M.; BILLINGS, M. Gifted children with Asperger's Syndrome. Gifted Child Quarterly, 44, 2000.

OUROFINO, V. T. A. T. Características cognitivas e afetivas entre alunos superdotados, hiperativos e superdotados/hiperativos: um estudo comparativo. Dissertação de Mestrado, Universidade de Brasília, Brasília, 2005.

RENZULLI, J. O que é essa coisa chamada superdotação, e como a desenvolvemos? Uma retrospectiva de vinte e cinco anos. Disponível em: http://revistaseletronicas. pucrs.br/ojs/index.php/faced/article/viewFile/375/272. Acesso em: 28 ago. 2011.

VIEIRA, N. J. Inteligências múltiplas e altas habilidades: uma proposta integradora para a identificação da superdotação. Linhas, Vol. 6, n. 2, 2005a. Disponível em: http://www.periodicos.udesc.br/index.php/linhas/article/viewFile/ 1270/1081. Acesso em: 07 jul. 2011. 
. "Viagem a Mojáve-Óki"! Uma trajetória na Identificação das altas habilidades/superdotação em crianças de quatro a seis anos. 2005. Tese (Doutorado) - Faculdade de Educação. Programa de Pós-graduação em Educação. Universidade Federal do Rio Grande do Sul. Porto Alegre, 2005b.

VIEIRA, N. J. W.; FREITAS, S. N. Procedimentos Qualitativos na Identificação das Altas Habilidades/Superdotação. In: BRANCHER, Vantoir Roberto e FREITAS, Soraia Napoleão de (Org.). Altas habilidades/ superdotação: Conversas e ensaios acadêmicos. Jundiaí, Paco Editorial: 2011.

WIDYORINI, E. Gifted children with asperger syndrom: emotional and social implications. Soegijapranata Catholic University, Indonesia. Disponível em: http://hkage.org.hk/en/events/080714\%20APCG/04$\% 20 \mathrm{Social} \% 20 \& \% 20 \mathrm{Em}$ ot i on al\% $20 \mathrm{Development/}$ 4.6\%20Widyorini_Gifted\%20Children\%20with\%20Asperger\%20Syndrom\%20Emotion.pdf. Acesso em: 07/09/2011.

Notas

${ }^{1}$ Manual para profissionais da área da saúde mental, que lista diferentes categorias de transtornos mentais e critérios para diagnosticá-los, de acordo com a Associação Americana de Psiquiatria.

\section{Correspondência}

Nara Joyce Wellausen Vieira - Parque Alto da Colina, Rua 02, casa 160, Bairro Camobi, CEP: 97110-560, Santa Maria, Rio Grande do Sul.

E-mail: najevars@yahoo.com.br - karolinasimon@gmail.com

Recebido em 14 de fevereiro de 2012

Aprovado em 18 de abril de 2012 